\title{
Inhibitory Effect of a Biscoclaurine Alkaloid, Cepharanthin, on Lung Metastasis of Lewis Lung Carcinoma
}

\author{
Hitoshi Ito, Hiroko Ito ${ }^{1}$, Hideomi Amano ${ }^{1}$ and Hiroyuki Noda ${ }^{1}$ \\ Department of Pharmacology, Mie University School of Medicine, Tsu, Mie 5I4, Japan \\ ${ }^{I}$ Laboratory of Marine Biochemistry, Faculty of Bioresources, Mie University, Tsu, Mie 514, Japan
}

Received January 24, 1991 Accepted March 22, 1991

\begin{abstract}
The antimetastatic effect of cepharanthin with or without 5-fluorouracil (5-FU) was examined in an experimental model of lung metastasis induced by Lewis lung carcinoma (3LL) in $\mathrm{C} 57 \mathrm{BL} / 6 \mathrm{crSlc}$ mice. Injection of cepharanthin i.p. after removal of the implanted primary tumor inhibited the development of lung metastases. Combination therapy with cepharanthin plus 5-FU inhibited significantly the lung metastases. Lung metastases were inhibited by i.v. injection of peritoneal macrophages activated with cepharanthin. Cepharanthin depressed aniline hydroxylase and aminopyrine demethylase activities of the hepatic microsomal drug-metabolizing system in tumor-bearing mice. Moreover, the concentration of 5-FU in the tissues (lung, liver, kidney, spleen and blood) was increased significantly by coadministration of cepharanthin. A possible mechanism of the inhibition of lung metastases by treatment with cepharanthin may be that this drug acts through macrophage activation and dcpression of the hepatic microsomal drug-metabolizing system. These findings raise the possibility that combination therapy with cepharanthin plus 5-FU may have clinical value in the prevention of cancer metastasis.
\end{abstract}

The pathogenesis of metastasis involves many complex biological processes, and its outcome depends on the interaction of tumor cells with their host and is influenced by various factors in the metastatic step $(1,2)$. The role of host defense in the control of metastasis is not well-understood. It might be possible to eradicate or prevent micrometastases by immunological modulation of the host defense mechanism. Indeed, biological response modifiers such as polysaccharides extracted from plants $(3,4)$, bacterial cellular components (5), Corynebacterium parvum (6), BCG (7) and water extract from herbal medicine (8) that activate the reticuloendothelial system of the host have been found to inhibit develop- ment of metastases. A pyrimidine antitumor drug, 5-fluorouracil (5-FU) has been proven to be one of the most useful drugs available in clinical oncology. A biscoclaurine alkaloid, cepharanthin, has been shown to affect cell membranes $(9-11)$ and alter the biomembrane movement of $\mathrm{Ca}^{++}(12)$. Shiraishi et al. (13) described the effect of cepharanthin on a multidrug resistance $\mathrm{KB}$ human cancer cell line. Kato and Suzumura (14) have reported that cepharanthin enhanced the antitumor activity of vincristine. Ono et al. (15) demonstrated that intratumoral administration of cepharanthin significantly inhibited the growth of Sarcoma-180 solid tumor in mice. Recently, Fujimura et al. (16) showed that cepharanthin 
overcomes doxorubicin resistance in doxorubicin-resistant murine P388 leukemia cells in vitro and in vivo. Shimura (17) demonstrated that cepharanthin enhanced phagocytosis and ingestion of polystyrene latex beads into the peritoneal macrophages of mice after i.p. injection. However, the mechanism of the action of cepharanthin on tumors, is still unclear.

Therefore in the present study, we attempted to determine the antimetastatic effect of cepharanthin on Lewis lung carcinoma and the possible mechanisms of its action.

\section{MATERIALS AND METHODS}

\section{Animals}

Five-week-old females C57BL/6crSlc mice (SPF), weighing 19 to $22 \mathrm{~g}$, were obtained from Shizuoka Laboratory Animal Center (Japan). They were maintained on an CE-2 pellet diet (Clea Japan, Inc., Japan) and water ad libitum.

\section{Tumor}

Lewis lung carcinoma (3LL) was initially supplied by the Aichi Cancer Center Institute. It was maintained by serial biweekly s.c. passage in $\mathrm{C} 57 \mathrm{BL} / 6 \mathrm{crSlc}$ mice. The tumor fragments were stirred in RPMI medium 1640 (Gibco Laboratories, Grand Island Biological Co., Grand Island, NY), containing $0.05 \%$ trypsin, at $30^{\circ} \mathrm{C}$ for $30 \mathrm{~min}$. After rinsing, the viability of the tumor cells was confirmed by the trypan blue dye exclusion method. A suspension of $10^{5}$ viable cells in $0.05 \mathrm{ml}$ of RPMI 1640 was implanted s.c. into the footpad of each mouse.

\section{Drugs}

Cepharanthin was kindly provided by Kaken Shoyaku Co., Ltd., Tokyo. The anticancer agent, 5-FU (Kyowa Hakko Kogyo Co., Ltd., Tokyo) was used as a reference drug in some of the experiments. The required concentrations of drugs were dissolved in $0.9 \% \mathrm{NaCl}$ solution for the study.

\section{Assay of lung metastases}

When the implanted tumor in the footpad had become about 4 to $5 \mathrm{~mm}$ in diameter 10 days after implantation of tumor cells, the mice were anesthetized by i.p. injection of 1 mg of sodium pentobarbital, and the tumorbearing leg was then surgically amputated. Mice were killed 14 days after removal of the implanted tumor, and their organs were examined grossly. The gross numbers of metastatic nodules were counted by Wexler's method (18).

\section{Preparation of effector cells}

Peritoneal exudate cells (PEC) were collected by washing the peritoneal cavity with 10 $\mathrm{ml}$ of RPMI 1640, 4 days after i.p. injection of cepharanthin. PEC were washed 3 times with medium and suspended at a fixed concentration in RPMI 1640 containing $10 \%$ fetal calf serum (FCS). For separation of adherent cells, suspensions of PEC were put into plastic flasks coated with serum and incubated at $37^{\circ} \mathrm{C}$ in a $5 \% \quad \mathrm{CO}_{2}$ incubator to allow macrophages to become attached by the method of Kumagai et al. (19). After incubation for 20 min, nonadherent cells were decanted, and flasks were washed 5 times with medium in an ice bath. Adherent cells were then removed from the flasks by incubation at $4^{\circ} \mathrm{C}$ in medium containing $0.2 \%$ EDTA and $5 \%$ FCS, washed, and resuspended in RPMI 1640.

\section{Assay of hepatic drug-metabolizing enzyme}

The activity of hepatic drug-metabolizing enzymes was assayed by the production of colored metabolites from aminopyrine and aniline after incubation with microsomes at $37^{\circ} \mathrm{C}$ in the presence of a NADPH-generating system (20) as described below. For the preparation of microsomes, a $25 \%$ liver homogenate in $0.25 \mathrm{M}$ sucrose was centrifuged at $10,000 \times$ $g$ for $20 \mathrm{~min}$ at $4^{\circ} \mathrm{C}$. The supernatant fraction was aspirated and centrifuged at $105,000 \times g$ for $60 \mathrm{~min}$ at $4 \mathrm{C}$. The microsomal pellet was washed by resuspension in ice-cold $0.15 \mathrm{M}$ $\mathrm{KCl}-10 \mathrm{mM}$ EDTA, followed by resedimentation at $105,000 \times g$ for $30 \mathrm{~min}$. The final pel- 
let was resuspended in an isotonic $\mathrm{KCl}$ solution.

For the aniline hydroxylase assay, each incubation mixture consisted of $5 \mu \mathrm{M}$ aniline, 2 $\mu \mathrm{M} \mathrm{NADP}^{+}, 25 \mu \mathrm{M}$ glucose-6-phosphate, 3.5 units of glucose-6-phosphate dehydrogenase, $25 \mu \mathrm{M}$ magnesium chloride and $1.0 \mathrm{ml}$ of microsomal suspension in a total volume of $5.0 \mathrm{ml}$ buffered at $\mathrm{pH} 7.4$ with $0.1 \mathrm{M}$ potassium phosphate. Reaction was initiated by the addition of microsomes. Incubations conducted in triplicate were carried out for $20 \mathrm{~min}$ at $37^{\circ} \mathrm{C}$ and terminated by the addition of $2 \mathrm{ml}$ of $20 \%$ trichloroacetic acid. Precipitated protein was removed by centrifugation, and aliquots of the clear supernatant were assayed for $p$-aminophenol at $630 \mathrm{~nm}$ in a spectrophotometer (Beckman Model 34, U.S.A.) according to the method of Kato and Gillette (21).

Aminopyrine demethylase assay was performed by the method of Farquhar et al. (20). Formaldehyde production from aminopyrine was reacted with Nash's reagent and determined by the method of La Du et al. (22) at $412 \mathrm{~nm}$ in a spectrophotometer (Hitachi 181 UV-VIS, Japan).

\section{Assay of 5-FU}

The assay of 5-FU in the tissue was measured as 5 -FU by a bioassay method using an indicator bacterium, Micrococcus luteus ATCC 10240 (23).

\section{Statistics}

The values are expressed as the means \pm S.E., and the statistical significances were determined with Student's $t$-test. Probabilities of less than $5 \%(\mathrm{P}<0.05)$ were considered significant.

\section{RESULTS}

Inhibition of growth of lung metastases by cepharanthin

The effect of cepharanthin on the growth of lung metastases of $3 \mathrm{LL}$ was examined by injecting cepharanthin into mice after removal of the implanted primary tumor. As shown in
Table 1, a single dose of $2.5,5.0$ or 10.0 $\mathrm{mg} / \mathrm{kg}$ was injected i.p. into mice on the day when the implanted tumor was removed. Significant inhibition of lung metastasis was noted in mice given injections of $10 \mathrm{mg} / \mathrm{kg}$ of cepharanthin (Table 1, Exp. 1). Subsequently, a dose of 5.0 or $10.0 \mathrm{mg} / \mathrm{kg}$ of cepharanthin was injected i.p. 3 times, once every 2 days, after removal of the tumor. The inhibition of lung metastasis was greatest at a dose of 5.0 $\mathrm{mg} / \mathrm{kg}$ (Table 1, Exp. 2). These results indicate that there is an optimal dose of cepharanthin for inhibition of lung metastases. A dose of $5.0 \mathrm{mg} / \mathrm{kg}$ of cepharanthin was injected i.p. 3 times, before and after removal of the implanted tumor. When cepharanthin was injected i.p. on days $3,5,7,9,10,12$ and 14 during growth of the implanted tumor, it caused significant inhibition of lung metastases (Table 1, Exp. 3). These results indicate that the inhibition of lung metastases depends on the time.

\section{Additive effects of cepharanthin and 5-FU on} lung metastases

The effect of combined therapy with cepharanthin and 5-FU on lung metastases was examined. The development of lung metastases was inhibited by each of these treatments alone, and the effects were additive (Table 2). In a preliminary experiment, the antitumor activity of the reference compound 5-FU at 30 $\mathrm{mg} / \mathrm{kg} /$ day was most effective in suppressing tumor growth and prevention of lung metastases. With a higher dose of $50 \mathrm{mg} / \mathrm{kg}$, however, the anti-metastatic effect was weaker than that of the control saline-treated group because of 5-FU toxicity (data not shown). An optimal dose of $5.0 \mathrm{mg} / \mathrm{kg}$ of cepharanthin and $30 \mathrm{mg} / \mathrm{kg}$ of $5-\mathrm{FU}$ were injected i.p., 3 times on days 10,12 and 14 after tumor implantation; this caused the most significant inhibition of lung metastases, and no metastatic nodules could be seen in 5 out of 10 mice. 
Table 1. Inhibition of lung metastases by cepharanthin

\begin{tabular}{|c|c|c|c|}
\hline \multirow{2}{*}{$\begin{array}{l}\text { Experimental } \\
\text { group }\end{array}$} & \multirow{2}{*}{$\begin{array}{c}\text { Dose } \\
(\mathrm{mg} / \mathrm{kg})\end{array}$} & \multirow{2}{*}{$\begin{array}{l}\text { Day of } \\
\text { injection }\end{array}$} & Lung metastases \\
\hline & & & No. of surface nodules \\
\hline \multicolumn{4}{|l|}{ Experiment 1} \\
\hline Control & & & $41.8 \pm 8.8$ \\
\hline \multirow[t]{3}{*}{ Cepharanthin } & 2.5 & 10 & $33.4 \pm 8.3$ \\
\hline & 5.0 & 10 & $28.9 \pm 8.7$ \\
\hline & 10.0 & 10 & $22.1 \pm 4.9^{*}$ \\
\hline \multicolumn{4}{|l|}{ Experiment 2} \\
\hline Control & & & $47.6 \pm 9.9$ \\
\hline Cepharanthin & 5.0 & $10,12,14$ & $21.9 \pm 5.8^{*}$ \\
\hline & 10.0 & $10,12,14$ & $25.5 \pm 6.7^{*}$ \\
\hline \multicolumn{4}{|l|}{ Experiment 3} \\
\hline Control & & & $43.3 \pm 7.9$ \\
\hline Cepharanthin & 5.0 & $\begin{array}{c}3,5,7,9 \\
10,12,14\end{array}$ & $16.4 \pm 4.8^{*}$ \\
\hline
\end{tabular}

Each experimental group consisted of 10 mice. Inocula of $10^{5}$ 3LL cells were implanted s.c. into one footpad of each mouse on day 0 . The implanted primary tumor was surgically removed by amputating the tumor-bearing leg on day 10 after tumor implantation. Cepharanthin was administered i.p. on day 10 (Exp. 1), on days 10, 12 and 14 (Exp. 2) or on days 3, 5, 7, 9, 10, 12 and 14 (Exp. 3). Control mice were given saline and vehicle in the same manner. Lung metastases were estimated 14 days after removal of the implanted tumor. Each valuc represents means \pm S.E. of 10 animals. Statistically significant difference from the control at ${ }^{*} \mathrm{P}<0.05$.

Table 2. Combined effect of cepharanthin and 5-FU on lung metastases

\begin{tabular}{|c|c|c|c|c|c|c|}
\hline \multirow[b]{2}{*}{$\begin{array}{l}\text { Experimental } \\
\text { group }\end{array}$} & \multicolumn{2}{|c|}{$5-\mathrm{FU}$} & \multicolumn{2}{|c|}{ Cepharanthin } & \multicolumn{2}{|c|}{ Lung metastases } \\
\hline & $\begin{array}{c}\text { Dose } \\
(\mathrm{mg} / \mathrm{kg})\end{array}$ & $\begin{array}{c}\text { Day of } \\
\text { injection }\end{array}$ & $\begin{array}{c}\text { Dose } \\
(\mathrm{mg} / \mathrm{kg})\end{array}$ & $\begin{array}{c}\text { Day of } \\
\text { injection }\end{array}$ & $\begin{array}{c}\text { No. of surface } \\
\text { nodules }\end{array}$ & Incidence \\
\hline Control & & & & & $39.2 \pm 7.1$ & $10 / 10$ \\
\hline Cepharanthin & & & 5.0 & $10,12,14$ & $19.1 \pm 4.7^{*}$ & $10 / 10$ \\
\hline 5-FU & 30 & $10,12,14$ & & & $10.6 \pm 3.2^{*}$ & $7 / 10$ \\
\hline 5-FU + Cepharanthin & 30 & $10,12,14$ & 5.0 & $10,12,14$ & $4.9 \pm 2.1^{* *}$ & $5 / 10$ \\
\hline
\end{tabular}

Each experimental group consisted of 10 mice. Inocula of $10^{5} 3 \mathrm{LL}$ cells were implanted s.c. into one footpad of each mouse on day 0 . The implanted primary tumor was surgically removed by amputating the tumor-bearing leg on day 10 after tumor implantation. Cepharanthin or 5-FU was administered i.p. on days 10,12 and 14. 5-FU was used as positive control drug. Control mice were given saline and vehicle in the same manner. Lung metastases were estimated 14 days after removal of the implanted tumor. Incidence are given as the ratio of number of mice with metastases/number of mice tested. Each value represents means \pm S.E. of 10 animals. ${ }^{*} \mathrm{P}<0.05$ compared with the controls (undergoing amputation only). ${ }^{* *} \mathrm{P}<0.05$, compared with use of 5-FU or cepharanthin by itself. 
Table 3. Effect of i.v. transfer of adherent cells from peritoncal exudate cells (PEC) activated with cepharanthin on lung metastases

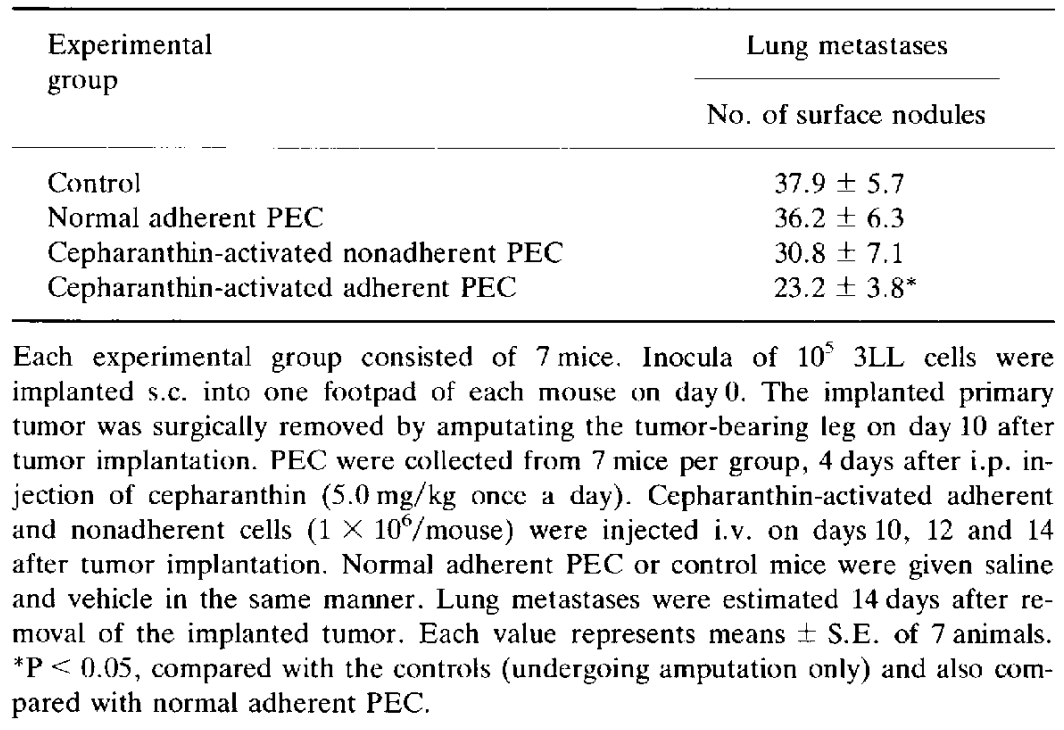

Inhibition of i.v. injection of peritoneal macrophages activated with cepharanthin on lung metastases

Peritoneal adherent cells from mice activated with cepharanthin were injected i.v. on days 10,12 and 14 into mice with lung metastases after tumor implantation. As shown in Table 3, a significant reduction in the number of metastatic nodules was observed in the lungs of mice given injections of peritoneal adherent cells activated with cepharanthin, but not in mice given injections of nonadherent cells treated with cepharanthin. Furthermore, no inhibition of metastases was seen in mice given injections of peritoneal adherent cells taken from normal mice. These results indicate that the transfer of peritoneal macrophages activated with cepharanthin has an inhibitory effect on lung metastases.

Effects of cepharanthin on drug-metabolism in the liver of $3 L L$-bearing mice

A single dose of cepharanthin $(5.0 \mathrm{mg} / \mathrm{kg})$ or $5-\mathrm{FU}(30 \mathrm{mg} / \mathrm{kg})$ plus cepharanthin $(5.0$ $\mathrm{mg} / \mathrm{kg}$ ) was injected i.p. into mice on the day the implanted primary tumor was removed. As shown in Fig. 1, aniline hydroxylase and

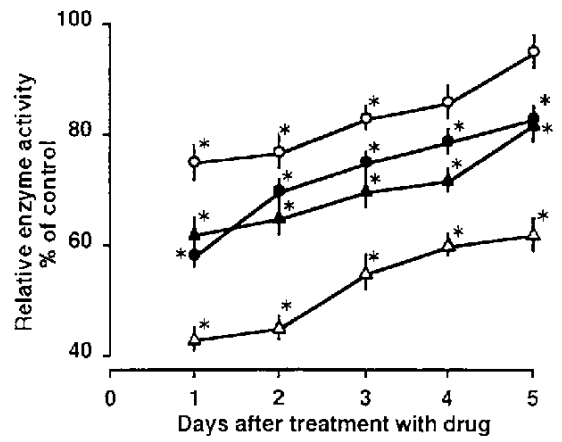

Fig 1. Time course of aniline hydroxylase and aminopyrine demethylase activities in hepatic microsomes of Lewis lung carcinoma-bcaring mice after a single i.p. injection of cepharanthin or 5-FU plus cepharanthin. Inocula of $10^{5} 3 \mathrm{LL}$ cells were implanted s.c. into one footpad of each mouse on day 0 . The implanted tumor was surgically removed by amputating the tumor-bearing leg on day 10 aftcr tumor implantation. Cepharanthin $(5.0 \mathrm{mg} / \mathrm{kg})$ or 5 -FU $(30 \mathrm{mg} / \mathrm{kg})$ was administered i.p. on day 10. Control mice were given saline and vehicle in the same manner. Animals were sacrificed at the indicated time after the injection of drug, and microsomes were prepared from their livers. Each point represents the percentage of the value obtained from the pooled mixture of the livers from 4 mice compared with the control. ${ }^{*} \mathbf{P}<0.05$, compared with the control value. Symbols: $(O, \triangle)$ aniline hydroxylase, $(\boldsymbol{O}, \boldsymbol{\Delta})$ aminopyrine demethylase, $(\mathrm{O}, \boldsymbol{O})$ cepharanthin, $(\triangle, \Delta) 5-F U+$ cepharanthin. 
aminopyrine demethylase activities of mice treated with cepharanthin (a single injection of $5 \mathrm{mg} / \mathrm{kg}$ ) were significantly inhibited compared to the saline-treated controls. The control values were as follows: aniline hydroxylase, $1.41 \pm 0.092(\mu \mathrm{M} / \mathrm{hr} / \mathrm{g}$ liver $)$; aminopyrine demethylase, $2.98 \pm 0.169(\mu \mathrm{M} / \mathrm{hr} / \mathrm{g}$ liver). Aniline hydroxylase activity was reduced more than aminopyrine demethylase activity. One day after the treatment with cepharanthin plus 5-FU, the activities for aniline hydroxylase and aminopyrine demethylase were reduced to approximately $48-60 \%$ of the controls, and they slowly recovered with the elapse of time, but aniline hydroxylase activity in the liver of the mice treated with cepharanthin plus 5-FU remained inhibited even on the 5 th day.

To examine whether cepharanthin has a modulating effect on the tissue 5-FU concentration, mice were administered i.p. with cepharanthin $(5 \mathrm{mg} / \mathrm{kg})$ or cepharanthin plus $5-\mathrm{FU}(30 \mathrm{mg} / \mathrm{kg})$. The concentration of $5-\mathrm{FU}$ in biological samples were measured as 5-FU at $6 \mathrm{hr}$ after the last treatment with the drug. 5-FU was present to a much greater extent in the liver, kidney, spleen, lung, and blood when it was administered in combination with cepharanthin (Table 4).

\section{DISCUSSION}

Tumor metastasis is established by a characteristic series of steps involving interaction with the extracellular matrix and basement membranes $(24,25)$. The inhibition and prevention of metastases are important problems in cancer therapy. It may be possible to inhibit metastasis, which is usually fatal in patients with malignant neoplasms. However, it is difficult to prevent overt metastasis or primary tumor growth. We used 3LL as an experimental model of spontaneous lung micrometastasis. In our model, the influence of the primary tumor on metastasis was excluded by removing the implanted tumor. Thus, this system seemed suitable for investigating the effects of host modulation on micrometastasis. We previously described that a blended Chinese medicine, Shōsaiko-Tō, inhibited the development of lung metastases in this model (8). Ono (26) has observed that oral administration of cepharanthin to tumor-bearing mice resulted in inhibition of $3 \mathrm{LL}$ primary tumor growth, preferential suppression of pulmonary metastases, and prolongation of survival time. By itself, cepharanthin was effective in preventing lung micrometastasis in syngeneic mice after the removal of $3 \mathrm{LL}$ implanted in the footpad (Table 1).

Table 4. Concentrations of 5-fluorouracil in various tissues from Lewis lung carcinoma-bearing mice after combination with cepharanthin

\begin{tabular}{|c|c|c|}
\hline \multirow[t]{2}{*}{ Tissues } & \multicolumn{2}{|c|}{$\begin{array}{l}\text { Concentration }(\mu \mathrm{g} / \mathrm{ml} \text { or } \mathrm{g} \text { wet weight }) \\
\text { of } 5-\mathrm{FU} \text { in tissues of mice treated with }\end{array}$} \\
\hline & 5-fluorouracil (5-FU) & 5-FU + Cepharanthin \\
\hline Blood & $0.041 \pm 0.007$ & $0.059 \pm 0.009^{*}$ \\
\hline Lung & $0.58 \pm 0.04$ & $0.91 \pm 0.14^{*}$ \\
\hline Liver & $0.42 \pm 0.12$ & $0.66 \pm 0.24^{*}$ \\
\hline Kidney & $1.24 \pm 0.34$ & $1.72 \pm 0.32^{*}$ \\
\hline Spleen & $2.37 \pm 0.98$ & $3.88 \pm 0.99^{*}$ \\
\hline
\end{tabular}

Inocula of $10^{5} 3 \mathrm{LL}$ cells were implanted s.c. into one footpad of each mouse on day 0 . The implanted tumor was surgically removed by amputating the tumor-bearing leg on day 10 after tumor implantation. Cepharanthin $(5.0 \mathrm{mg} / \mathrm{kg}$ ) or 5 -FU (30 $\mathrm{mg} / \mathrm{kg}$ ) was administered i.p. on days 10,12 and 14 . The concentration in tissues were calculated as 5-FU at $6 \mathrm{hr}$ after the last treatment with drug. Each value represents means $\pm S$.E. of triplicate determinations from 5 mice in a group. $* \mathbf{P}<$ 0.05 , compared with the 5-FU-treated group. 
We found that cepharanthin plus 5-FU had additive inhibitory effects in an experimental lung metastasis model (Table 2). Several interpretations of this are possible: 1) The liver drug-metabolizing system was suppressed by treatment with cepharanthin (Fig. 1), resulting in the increase of 5-FU in the tissues. 2) The cytotoxicity of 5-FU was enhanced by the administration of cepharanthin. 3) The tumor cells sterilized by 5 -FU might have released abundant antigens, which led to an enhanced immune response. Although the present results do not clarify what mechanism is involved in the combined effect, the experimental results indicate that cepharanthin can serve as an excellent adjuvant to anticancer drugs.

Shimura has been reported that cepharanthin enhanced phagocytosis in the peritoneal macrophages of mice and the third component of the complement system was activated by the i.p. injection of cepharanthin (17). Ito et al. (27) reported that adherent PEC, harvested from mice after i.p. injections of squalene-treated Nocardia rubra cell wall skeleton, showed cytolytic activity on tumor target cells in vitro. They also found that this activity was markedly inhibited by treatment with antimacrophage serum and complement or carrageenan. Moreover, Liotta et al. (28) reported that the i.v. transfer of BCG-activated peritoneal exudate cells inhibited lung metastasis in mice that had been implanted with $\mathbf{T}_{241}$ fibrosarcomas. Furthermore, Sone et al. (29) demonstrated that after direct stimulation with Nocardia rubra cell wall skeleton, alveolar macrophages became tumorcidal against syngeneic, allogeneic and xenogeneic tumor cells in vitro. We have here demonstrated that i.p. injections of adherent PEC activated with cepharantin inhibit the development of lung micrometastasis in mice. In addition, the antimetastatic effect was not observed when 3LL-bearing mice were injected i.p. with a blocker of immunocompetent cells, carrageenan ( $2 \mathrm{mg} / \mathrm{mouse})$ on days 10,12 and 14 after tumor implantation $(H$. Ito et al., unpublished data). Thus, the anti- metastatic activity of cepharanthin on $3 \mathrm{LL}$ seems to be mediated by the activation of macrophages. In our tests for the toxicity of cepharanthin, the concentrations of cepharanthin used in the present study did not have any side effects such as diarrhea, decrease of body weight, abnormal behavioral changes or decreases of food consumption and water intake. These findings at least indicate that cepharanthin might be a useful agent in the clinic for the prevention of cancer metastasis.

\section{REFERENCES}

1 Poste, G. and Fidler, I.J.: The pathogenesis of cancer metastasis. Nature 283, $139-146$ (1980)

2 Tsubra, E., Yamashita, T., Yamamoto, T. and Kagawa, K.: Biological aspects of cancer metastasis-a review. Japan. J. Clin. Oncol. 11, $145-158(1981)$

3 Proctor, J.W., Auclair, B.G., Stokowski, L., Mansell, P.W.A. and Shibata, H.: Comparison of effects of BCG, glucan, and levamisole on B16 melanoma metastases. Eur. J. Cancer 13, 115-122 (1977)

4 Yamamoto, T., Yamashita, T. and Tsubura, E.: Inhibition of pulmonary metastasis of Lewis lung carcinoma by a glucan, Schizophyllan. Invasion Metastasis 1,71-84 (1981)

5 Ogura, T., Namba, N., Hirao, F., Yamamura, Y. and Azuma, I.: Association of macrophage activation with antitumor effect on rat syngeneic fibrosarcoma by Nocardia rubra cell wall skeleton. Cancer Res. 39, 4706-4712 (1979)

6 Mosley, J.G., Sadler, T.E. and Castro, J.E.: Effects of amputation and Corynebacterium parvum on tumor metastases in mice. Br. J. Cancer 37, $571-575$ (1978)

7 Kreider, J.W., Bartlett, G.L., Boyer, C.M. and Purnell, D.M.: Conditions for effective Bacillus Calmette-Guerin immunotherapy of post surgical metastases of 13762A rat mammary adenocarcinoma. Cancer Res. 39, 987-992 (1979)

8 Ito, H. and Shimura, K.: Effects of a blended Chinese medicine, Xiao-Chai-Hu-Tang, on Lewis lung carcinoma growth and inhibition of lung metastasis, with special reference to macrophage activation. Japan. J. Pharmacol. 41, 307-314 (1986)

9 Fuji, T., Sato, T., Tamura, A., Wakatsuki, M. and Kanaho, Y.: Sharp changes of human erythrocytes induced by various amphipathic drugs acting on the membrane of the intact cells. Biochem. 
Pharmacol. 28, 613-620 (1979)

10 Watanabe, S.: Inhibition of platelete aggregation by cepharanthin is accomplished during the early, membrane-related activation process. Acta Med. Okayama 38, 101-115 (1984)

11 Utsumi, K., Miyahara, M., Sugiyama, K. and Sasaki, J.: Effect of biscoclaurin alkaloid on the cell membrane related to membrane fluidity. Acta Histochem. Cytochem. 9, 59-68 (1976)

12 Nagatsuka, S. and Nakazawa, T.: Effect of membrane-stabilizing agents, cholesterol and cepharanthin on radiation-induced lipid peroxidation and permeability in liposomes. Biochim. Biophys. Acta 691, 171-177 (1982)

13 Shiraishi, N., Akiyama, S., Nakagawa, M., Kobayashi, M. and Kuwano, M.: Effect of bisbenzylisoquinoline (biscoclaurine) alkaloids on multidrug resistance in $\mathrm{KB}$ human cancer cells. Cancer Res. 47, 2413-2416 (1987)

14 Kato, T. and Suzumura, Y.: Potentiation of antitumor activity of vincristine by the biscoclaurine alkaloid cepharanthin. JNCI 79, 527-532 (1987)

15 Ono, M., Tanaka, N., Orita, K., Yatabe, M. and Akasu, M: Direct effect of cepharanthin on growth-inhibitory action of pretreated Sarcoma-180 cells in vivo. Ther. Res. 8, 263-268 (1988) (Abs. in English)

16 Fujimura, T., Shibata, H., Maekawa, I., Furusawa, S., Kawauchi, H., Sasaki, K. and Takayanagi, Y.: Reversal of resistance to doxorubicin with cepharanthin in murine P388 lcukemia cells. Japan. J. Pharmacol. 54, 464-467 (1990)

17 Shimura, K.: Effect of cepharanthin on complement $\mathrm{C} 3$ and peritoneal macrophages in mice. Japan. Pharmacol. Ther. 17, 239-243 (1989) (Abs. in English)

18 Wexler, H.: Accurate identification of experimental pulmonary metastases. JNCI 36, 641645 (1966)

19 Kumagai, K., Ito, K., Hinuma, S. and Tada, M.: Pretreatment of plastic petri dishes with fetal calf serum. A simple method for macrophage isolation. J. Immunol. Methods 29, 17-25 (1979)

20 Farquhar, D., Loo, T.L., Gutterman, J.U.,
Hersh, E.M. and Luna, M.A.: Inhibition drug metabolizing enzymes in the rat after Bacillus Calmette-Guerin treatment. Biochem. Pharmacol. 25, $1529-1535$ (1976)

21 Kato, R. and Gillette, J.R.: Effect of starvation on NADPH-dependent enzymes in liver microsomes of male and female rats. J. Pharmacol Exp. Ther. 150, 279-284 (1965)

22 La Du, B.B., Gaudette, L., Trousof, N. and Brodie, B.B.: Enzymatic dealkylation of aminopyrine (pyramidon) and other alkylamines. J. Biol. Chem. 214, $741-752$ (1955)

23 Itsumi, S., Maeda, K. and Fugono, T.: Measurement of 1-(tetrahydro-2-furanyl)-5-fluorouracil (TF) and 5-fluorouracil (5-FU) concentrations by bioassay method with Micrococcus luteus ATCC 10240 strain. Clin. Rep. 13, $49-54$ (1979) (Abs. in English)

24 Liotta, L.A., Rao, C.V. and Barsky, S.H.: Tumor invasion and the extracellular matrix. Lab. Invest. 49, 636-649 (1983)

25 Terranova, V.P., Williams, J.E., Liotta, L.A. and Martin, G.R.: Modulation of the metastatic activity of melanoma cells by laminin and fibronectin. Science 226, 982-984 (1984)

26 Ono, M.: Antitumor effect of cepharanthin: Mechanism of antimetastatic effect on Lewis lung carcinoma (3LL). Japan. J. Cancer Chemother. 15, $249-255$ (1988) (Abs. in English)

27 Ito, M., Iizuka, H., Masuno, T., Yasunari, R., Ogura, T., Yamamura, Y. and Azuma, I.: Killing of tumor cells in vitro by macrophages from mice given injections of squalene-treated cell wall skeleton of Nocardia rubra. Cancer Res. 41, 2925 - 2930 (1981)

28 Liotta, L.A., Gattozzi, C., Kleinerman, J. and Saidel, G.: Reduction of tumor cell entry into vessels by BCG-activated macrophages. Br. J. Cancer 36, 639-641 (1977)

29 Sone, S., Pollack, V.A. and Fidler, I.J.: Direct activation of tumoricidal properties in rat alveolar macrophages by Nocardia rubra cell wall skeleton. Cancer Immunol. Immunother. 9, 227 - 232 (1980) 